\title{
Secondary Dystonia-Clinical Clues and Syndromic Associations
}

\author{
Susanne A Schneider ${ }^{a}$ \\ Kailash P Bhatia ${ }^{\text {b }}$
}

asection of Clinical and Molecular Neurogenetics at the Department of Neurology, University Luebeck, Maria-Goeppert-Str. 1, Luebeck, Germany and Sobell Department of Motor Neuroscience and Movement Disorders, Institute of Neurology, University College London, Queen Square, London, U.K.

bSobell Department of

Motor Neuroscience and Movement Disorders, Institute of Neurology, University College of London, Queen Square, London, U.K.

Received October 13, 2009 Accepted October 15, 2009

\footnotetext{
Corresponding author Kailash P Bhatia, MD

Sobell Department of Motor

Neuroscience and Movement Disorders, Institute of Neurology,

University College London,

Queen Square, London

WC1N 3BG, U.K.

E-mail kbhatia@ion.ucl.ac.uk
}

Background: Dystonia is a hyperkinetic movement disorder defined by involuntary sustained muscle spasms and unusual postures. Etiologically, dystonic syndromes can be broadly divided into primary and secondary forms, dystonia-plus syndromes and heredodegenerative forms. In particular, diagnosis of secondary dystonic syndromes can be challenging in view of the variety of causes. Purpose: The purpose of this article is to highlight some clinical clues and syndromic associations as well as investigational findings which may be helpful in the approach to a patient with suspected secondary dystonia. Methods: We outline characteristic clinical and neuroimaging findings which may be directive in the diagnostic process of dystonia patients and facilitate making the correct diagnosis, thus allowing initiating the best treatment. Results: Secondary causes of dystonia include, among others, strategic brain lesions of various origins, metabolic disease, neurodegenerative conditions, and previous exposure to drugs or toxins. Presence of clinical signs including prominent oromandibular involvement, eye movement disorders, retinitis pigmentosa, deafness, peripheral neuropathy, parkinsonism or progressive dementia should alert the clinician to consider a secondary cause. Strategic lesions within the basal ganglia, but also within the brainstem, cerebellum or cortical areas may underlie dystonia and should thus be excluded. Conclusions: When thorough clinical examination reveals features atypical of primary dystonia, syndromic associations may help the clinician to narrow down the list of differential diagnosis. Directive investigations like neuroimaging may confirm the clinical suspicion.

Journal of Movement Disorders 2009;2:58-63

Key Words: Chorea, Brain infarction, Anterior cerebral artery.

\section{Introduction and Methods}

Dystonia is a hyperkinetic movement disorder characterized by involuntary sustained muscle spasms causing in twisting movements and abnormal posturing of one or multiple body parts. Dystonia syndromes can be classified by onset age, distribution and etiology. With respect to the latter, dystonic syndromes can be divided into primary and secondary forms, dystonia-plus syndromes and heredodegenerative forms. While numerous authors have reviewed the primary dystonias ${ }^{1}$ in recent years, highlighting the proceedings into genetics and other aspects of the primary dystonias, less emphasis has been given to the secondary forms, albeit exigent.

In this article we chose to focus on secondary dystonias, in particular, because their diagnosis can be challenging. Causes are multifold and include brain lesions of various nature, previous exposure to drugs (in particular dopamine antagonists) or toxins, metabolic conditions and neurodegeneration. Fortunately, combination of clinical features ("syndromic associations") may serve as red flag towards certain syndromes and investigations may demonstrate characteristic findings which may confirm the diagnosis or be directive in the diagnostic process and facilitate making the correct diagnosis and thus allow initiating the ideal treatment.

In this article we point out some clinical clues and syndromic associations which may be helpful in the approach to a patient. 


\section{Results}

\section{Prevalence of secondary dystonia}

How common is secondary dystonia? Prevalence data on secondary dystonia are limited. A Brazilian study of 122 patients with a dystonic syndrome, $46(38 \%)$ were found to have a symptomatic form. ${ }^{2}$ Among these, the most frequent causes were tardive dystonia (35\%) and perinatal cerebral injury $(30 \%)$. Other causes included stroke (13\%), encephalitis $(6.5 \%)$ and Wilson's disease (4\%). Causes were more common in certain age groups: Younger patients tended to have had perinatal cerebral injury or encephalitis preceeding their dystonia. In older patients stroke and exposure to drugs (tardive dystonia) were more common. In a recent study by Wenning et al. $^{3}$ of 16 elderly patients with dystonia, ten $(62.5 \%)$ were classified as having a secondary form of dystonia. Of these, eight were drug-induced, highlighting the importance of this etiology. This is in line with a large study of more than 3,000 dystonia patients, $29 \%$ of which had a secondary form:tardive dystonia was the leading cause. ${ }^{4,5}$

However, in addition to tardive dystonia, there are a number of other secondary and heredodegenerative disorders which can cause dystonia as a predominant feature or as part of a syndrome. Certain clinical clues may help to narrow down the list of differential diagnoses and focus the investigations accordingly (Table 1).

\section{Clinical clues}

\section{Dystonia with prominent oro-bulbar involvement}

Some primary dystonias there may have laryngeal involvement, for example DYT4 ("whispering dystonia", the underlying gene remains unkown), DYT6 (due to mutations in the THAP1 gene, as very recently identified), DYT12 ("rapidonset dystonia parkinsonism") and DYT17 (recessively inherited, linked to the chromosome 20, gene not yet identified) dystonia. ${ }^{6-8}$ However, overall, prominent oro-lingualbuccal dystonia is uncommon in primary dystonia and a secondary or heredodegenerative form should be considered, ${ }^{9}$ particularly, when severe (Table 1). In particular pervious neuroleptic intake, but also certain genetic disorders such as PKAN (pantothenate kinase associated neurodegeneration, previously known as Hallervorden-Spatz disease) due to mutations of the PANK2 gene, neuroacanthocytosis, neuroferritinopathy and Lesch-Nyhan syndrome are high on the list of differentials. ${ }^{10}$ With the exception of neuroferritinopathy (autosomal dominant inheritance) they follow autosomal recessive inheritance and family history may thus be negative for a similar disorder, but there may be a history of consanguinity.

\section{Eye movement disorders}

Patients with primary dystonia have normal eye move-
Table 1. Clinical features suggestive of secondary dystonia

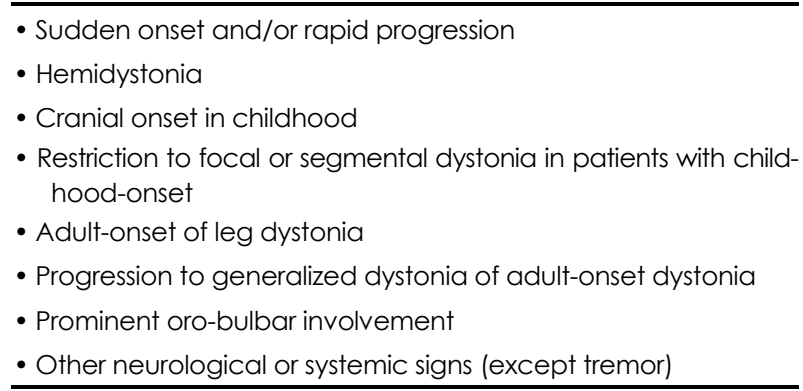

ments. In fact, presence of an eye movement disorder hints towards a secondary form of dystonia.

Eye movement dysfunction may be in the form of supranuclear gaze palsy. Patients with a supranuclear gaze palsy may complain of difficulties going downstairs because of limited downward gaze which is usually more affected than upward gaze. Presence is limited to a few dystonic conditions, most importantly progressive supranuclear palsy (PSP), where parkinsonism is the prominent and patients are elderly. Furthermore, supranuclear palsy may be present in Niemann-Pick type $\mathrm{C}$ and PKAN, both inherited autosomal recessively. In Niemann-Pick type C, a neurovisceral lipid storage disorder, supranuclear gaze palsy is present in $75 \%$ of adult-onset cases and a presenting sign in $8 \%$ of cases. ${ }^{10}$

\section{Dystonia and retinitis pigmentosa}

The presence of retinitis pigmentosa in the context of dystonia narrows down the list of differential diagnoses. Most important differential diagnoses in this context are PKAN (or the allelic disorder referred to as HARP syndrome characterized by hypoprebetalipoproteinemia, acanthocytosis, retinitis pigmentosa, and pallidal degeneration), GM2 gangliosidosis and metachromatic leukodystrophy.

\section{Dystonia and deafness}

The combination of dystonia and deafness is characteristic of the Mohr-Tranebjaerg syndrome due to a new mutations in the DDP1 gene. ${ }^{11}$ Other mitochondrial disorders may produce a complex phenotype which may involve additional visual problems (blindness) or heart problems. ${ }^{12}$

Another complex disorder with phenotypic similarities to mitochondrial disease is the Woodhouse-Sakati syndrome. For this, only recently the underlying cause was identified and effects the $\mathrm{C} 2$ orf37 gene, encoding a nucleolar protein. ${ }^{13}$ This rare autosomal recessive disorder presents with hypogonadism, alopecia, diabetes mellitus, mental retardation, and extrapyramidal features. ${ }^{14}$ As for other genetic disorders, there is phenotypic and genetic variability.

\section{Dystonia and peripheral neuropathy}

Presence of neuropathy is not a feature of primary dysto- 
nia, although subclinical impairment of sensory discrimination is discussed as possible endophenotype of dystonia. ${ }^{15}$

If ataxia is additionally present, there are, however, a number of differentials to consider. This includes the common recessive forms of ataxia, such as Friedreich's ataxia ${ }^{16}$ and ataxia telangiectasia ${ }^{17,18}$ and their differential diagnoses, ${ }^{19}$ where ataxia, dystonia and peripheral neuropathy may be present. For example, in a study of 70 ataxia telangiectasia patients, dystonia was present in 55 and peripheral neuropathy 50 of them. ${ }^{20} \mathrm{~A}$ less common cause is the young-onset variant of Niemann-Pick type $\mathrm{C}$ disease, while the adult form presents with peripheral nervous system involvement. ${ }^{11} \mathrm{Be}$ cause presence of vertical gaze palsy is also characteristic (see above) in Niemann-Pick type $\mathrm{C}$, which is present in $75-80 \%$ of patients, this can be a helpful clue towards the diagnosis. A further clue may be enlargement of the liver and spleen (present in about one $30-90 \%$ of cases) ${ }^{11,21}$ and, in children, neonatal jaundice (present in half of the patients).

Notably, the combination of dystonia with neuropathy and ataxia can also be seen in some of the autosomal dominant spinocerebellar ataxias, ${ }^{22}$ e.g. SCA $3 .^{23}$

Finally, the combination of peripheral neuropathy, progressive dystonia and ataxia, as well as cognitive decline is seen in metachromatic leukodystrophy caused by mutations in the arylsulfatase A gene cause. ${ }^{24}$

\section{Dystonia and parkinsonism}

In addition to pure dystonic and pure parkinsonian syndromes, there are overlap syndromes. On one hand dystonic conditions may have superimposed parkinsonism as seen in dopa-responsive dystonia or Wilson's disease. On the other hand, dystonia may be a seen in (or even be the presenting feature of) various parkinsonian disorders.

While dystonia is uncommon in drug-naive patients with idiopathic Parkinson's disease, its presence may be a red flag towards an atypical parkinsonian syndrome like PSP, multiple system atrophy (MSA) or corticobasal degeneration (CBD) ${ }^{25}$ Dystonia may then present as axial dystonia and blepharospasm (levator inhibition) causing the starring expression associated with PSP; antecollis and facial dystonia in MSA; or the dystonic arm posture seen in CBD.

Parkinsonism associated with dystonia is furthermore characteristic of genetic forms of parkinsonism which often have young-onset and recessive inheritance (for review see). ${ }^{26,27}$ One example is parkinsonism related to mutations in the Parkin gene where dystonia may be present intermittently, as so-called exercise-induced paroxysmal foot dystonia, and this may precede signs of parkinsonism by some years. ${ }^{28}$ The combination of young-onset dystonia and parkinsonism is also seen in other neurodegenerative diseases like the rare autosomal recessive disorders of nigro-striatal-pallidal-pyramidal syndrome referred to as Kufor-Rakeb disease and
PLA2G6-associated neurodegeneration (PARK14). ${ }^{29}$ (also see review by Schneider, et al. ${ }^{26}$ )

Most frequent, however, is dystonia in the context of parkinsonism as complication of dopaminergic treatment, for example as peak-dose dystonia, diphasic dystonia and offdystonia. $^{28}$

\section{Dystonia with progressive dementia}

Progressive dementia is not a feature of the primary dystonias like the young-onset DYT1-related dystonia or the adult-onset sporadic forms. Progressive dementia is, however, one of the core features of Huntington's disease and the Huntington disease-look like syndromes (including HDL4/ SCA17), as well as neuroacanthocytosis and PKAN. Indeed, chorea is the main movement disorder, however, prominent dystonia can occur. A further condition to consider is Creutzfeldt-Jakob disease, a rare neurodegenerative disease characterized by rapidly progressive dementia, mutism, ataxia and extrapyramidal and pyramidal involvement. ${ }^{30}$ The movement disorder is typically characterized by focal or generalized myoclonus (present in $80-100 \%$ of cases), but dystonia occurs and may rarely be a presenting sign. ${ }^{30-32}$ Dystonia in Creutzfeldt-Jakob disease is then usually unilateral and distally but may become generalized in later disease stages. ${ }^{30}$ Over all, disease course is rather progressive and this should alert the clinician to this diagnosis. Furthermore, HIV encephalopathy is a cause of dementia; and dystonia has also been observed. ${ }^{33}$

Finally, dementia may also be a symptom in the complex autosomal recessive dystonia parkinsonian syndromes mentioned above. ${ }^{26}$

\section{Clues from neuroimaging}

Neuroimaging can reveal patterns characteristic of certain conditions. Strategic lesions in the basal ganglia, brainstem, cerebellum or cortical areas (parietal and frontal) may result in dystonia ${ }^{34-41}$ and there may be a relationship between the distribution of dystonia and the localization of the lesion. For example, it has been proposed that thalamic lesions are more likely to result in hand dystonia. However, not all basal ganglia lesions necessarily result in neurological symptoms or signs. Brainstem lesions on the other hand have been associated with cranial dystonias such as blepharospasm, and putaminal lesions were found in patients with hemidystonia or limb dystonia. In hemidystonia, lesions are often unilateral, contralaterally to the dystonia.

Of course, the list of causes underlying the lesion is long and includes tumors, trauma, bleeding, inflammation, atrophic changes in the context of neurodegeneration or accumulation of metals (such as iron, copper, manganese etc.).

How imaging can facilitate the diagnostic work-up we will be discussed in more detail as an example for basal 
ganglia disorders with metal deposition. The basal ganglia host high concentrations of metals which act as cofactors for metabolic activity including iron, copper and manganese. In the case of excessive metal accumulation, this may cause dysfunction and disease.

Metal deposition can be detected by neuroimaging on CT (e.g. copper) or MRI (e.g. iron). In recent years, in particular, iron deposition has received growing attention and a new term referring to these disorders, "syndromes of neurodegeneration with brain iron accumulation" (NBIA), has been coined. This group entails the condition of PKAN (NBIA type 1, also known as Hallervorden-Spatz disease), PLA2G6-associated neurodegeneration (NBIA type 2), ${ }^{29}$ neuroferritinopathy, and aceruloplasminemia. ${ }^{42,43}$

Of these, in PKAN iron accumulates within the globus pallidus interna. T2-weighted MRI demonstrates a signal hypointensity representing iron with a central hyperintensity (probably representing fluid accumulation or edema) and this pattern resembles an eye of the tiger on axial slides. ${ }^{42}$ It has been proposed that this 'eye-of-the-tiger' sign highly correlates with the genoptype, thus with presence of PANK2 gene mutations, ${ }^{42,44}$ and that it is usually present from early in the disease course ${ }^{45}$ although this is still matter of debate. NBIA type 2 is associated with mutations in the PLA2G6 gene on chromosome $22 \mathrm{q} 13$, a calcium-independent phospholipase. The clinical phenotype is heterogenous and includes infantile neuroaxonal dystrophy and adolesecence/adult-onset dystonia parkinsonism, and it is a key differential diagnosis of PKAN. As in PKAN there is iron deposition on MRI imaging, however there is no classical eye-of-the-tiger sign, but there is only a hypointensity in the globus pallidus, whereas the central hyperintensity is lacking. Notably, though, normal MRI imaging has also been reported in a gene-proven case of PLA2G6-associated neurodegeneration and the disorder should thus also be considered when iron is absent. ${ }^{29}$

Copper deposition also shows as hyperintense signal on T2-weighted scans. Copper deposition in the putamen and globus pallidus, liver and cornea are characteristic of Wilson's disease, an important differential diagnosis of secondary dystonia, particularly in young patients. ${ }^{46,47}$ This is known as "face of the giant panda" sign (referring to the combination of high signal intensity in the tegmentum except for the red nucleus with preservation of signal intensity of the lateral portion of the pars reticulata of the substantia nigra and hypointensity of the superior colliculus). ${ }^{48}$

Manganese accumulation has been associated with secondary parkinsonism in welders chronically exposed. In the basal ganglia manganese accumulates symmetrically within the globus pallidum and is depicted as hyperintensity on T1 sequences. Dystonia may also be prominent. ${ }^{49-52}$

Calcium deposition can be easily detected by $\mathrm{CT}$ imaging as high-intense lesions and incidental calcifications are rel- atively frequent (up to $1.5 \%$ of CT scans). Within the basal ganglia, calcium mostly commonly affects the globus pallidus and is usually benign, in most cases idiopathic or agerelated. ${ }^{53}$ In view of this, it has been proposed that presence of globus pallidus calcifications only requires further elaboration when the patient is younger than 40 years of age. In addition all patients, no matter of age, where other basal ganglia or brain areas are affected should be further investigated. The differential diagnosis is wide and includes metabolic, infectious, toxin-induced and degenerative causes. ${ }^{53}$ Among the metabolic disorders, idiopathic or surgical hypoparathyroidism is probably the most common cause of symmetric basal ganglia calcification, and dystonia as presenting feature may occur. ${ }^{54}$ Infections (including congenital forms) by toxplasmosis, rubella, cytmomegaly, herpes and HIV may result in basal ganglia damage with calcifications and secondary dystonia. ${ }^{55,56}$ Following carbon monoxide poisoning movement disorders including dystonia may develop as a part of delayed encephalopathy ${ }^{57}$ and imaging may reveal basal ganglia calcifications. ${ }^{58}$ Neurodegenerative causes include Wilson's disease. ${ }^{59}$

Last but not least, familial causes of basal ganglia calcifications have been recognized, also referred to as striopallidodentate calcinosis or Fahr's disease and dystonia has been observed. ${ }^{59}$

\section{Conclusions}

While presence of tremor is compatible with a diagnosis of primary dystonia, there are other clinical features which point away from this diagnosis, including eye movement disorders, retinitis pigmentosa or peripheral neuropathy, to name a few. In these cases syndromic associations, some of which have been outlined in this article, can be useful and help the clinician to narrow down the list of differential diagnosis. Investigations such as a peripheral blood smear to screen for neuroacathocytosis or neuroimaging may help to reach at the correct diagnosis.

\section{REFERENCES}

1. Bressman S. Genetics of dystonia. J Neural Transm Suppl 2006;489-495.

2. Andrade LA, Ferraz HB. Idiopathic dystonia. Clinical profile of 76 Brazilian patients. Arq Neuropsiquiatr 1992;50:426-432.

3. Wenning GK, Kiechl S, Seppi K, Müller J, Högl B, Saletu M, et al. Prevalence of movement disorders in men and women aged 50-89 years (Bruneck Study cohort): a population-based study. Lancet Neurol 2005;4:815-820.

4. Bressman S. Overview of dystonia. In: Adler $\mathrm{CH}$, ed. Clinical usefulness of Botulinum Toxin and Treatment of Dystonia. Minneapolis, MN: American Academy of Neurology 2002:2-30.

5. Uc EY, Rodnitzky RL. Juvenile parkinsonism. Semin Pediatr Neurol 2003;10:62-67.

6. Djarmati A, Schneider SA, Lohmann K, Winkler S, Pawlack H, Hagenah J, et al. Mutations in THAP1 (DYT6) and generalised dystonia with prominent spasmodic dysphonia: a genetic screening study. Lancet 
Neurol 2009;8:447-452.

7. Ahmad F, Davis MB, Waddy HM, Oley CA, Marsden CD, Harding AE. Evidence for locus heterogeneity in autosomal dominant torsion dystonia. Genomics 1993;15:9-12.

8. Chouery E, Kfoury J, Delague V, Jalkh N, Bejjani P, Serre JL, et al. A novel locus for autosomal recessive primary torsion dystonia (DYT17) maps to 20p11.22-q13.12. Neurogenetics 2008;9:287-293.

9. Schneider SA, Aggarwal A, Bhatt M, Dupont E, Tisch S, Limousin P, et al. Severe tongue protrusion dystonia: clinical syndromes and possible treatment. Neurology 2006;67:940-943.

10. Sévin M, Lesca G, Baumann N, Millat G, Lyon-Caen O, Vanier MT, et al. The adult form of Niemann-Pick disease type C. Brain 2007; 130:120-133.

11. Jin H, May M, Tranebjaerg L, Kendall E, Fontán G, Jackson J, et al. A novel X-linked gene, DDP, shows mutations in families with deafness (DFN-1), dystonia, mental deficiency and blindness. Nat Genet 1996;14:177-180.

12. Zeviani M, Di Donato S. Mitochondrial disorders. Brain 2004;127: 2153-2172.

13. Alazami AM, Al-Saif A, Al-Semari A, Bohlega S, Zlitni S, Alzahrani $\mathrm{F}$, et al. Mutations in C2orf37, encoding a nucleolar protein, cause hypogonadism, alopecia, diabetes mellitus, mental retardation, and extrapyramidal syndrome. Am J Hum Genet 2008;83:684-691.

14. Schneider SA, Bhatia KP. Dystonia in the Woodhouse Sakati syndrome: a new family and literature review. Mov Disord 2008;23:592596.

15. Walsh R, O’Dwyer JP, Sheikh IH, O'Riordan S, Lynch T, Hutchinson M. Sporadic adult onset dystonia: sensory abnormalities as an endophenotype in unaffected relatives. J Neurol Neurosurg Psychiatry 2007;78:980-983.

16. Garcia Ruiz PJ, Mayo D, Hernandez J, Cantarero S, Ayuso C. Movement disorders in hereditary ataxias. J Neurol Sci 2002;202:59-64.

17. Woods CG, Taylor AM. Ataxia telangiectasia in the British Isles: the clinical and laboratory features of 70 affected individuals. Q J Med 1992;82:169-179.

18. Carrillo F, Schneider SA, Taylor AM, Srinivasan V, Kapoor R, Bhatia KP. Prominent oromandibular dystonia and pharyngeal telangiectasia in atypical ataxia telangiectasia. Cerebellum 2009;8:22-27.

19. Le Ber I, Bouslam N, Rivaud-Péchoux S, Guimarães J, Benomar A Chamayou $\mathrm{C}$, et al. Frequency and phenotypic spectrum of ataxia with oculomotor apraxia 2: a clinical and genetic study in 18 patients Brain 2004;127:759-267.

20. Woods CG, Taylor AM. Ataxia telangiectasia in the British Isles: the clinical and laboratory features of 70 affected individuals. Q J Med 1992;82:169-179.

21. Garver WS, Francis GA, Jelinek D, Shepherd G, Flynn J, Castro G, et al. The National Niemann-Pick C1 disease database: report of clinical features and health problems. Am J Med Genet A 2007;143A: 1204-1211.

22. Klockgether T. Hereditary Ataxias. In: Jankovic J, Tolosa E, eds. Parkinson's Disease and Movement Disorders, 5ed. Philadelphia: Lippincott Williams \& Wilkins, 2007:421-435.

23. Klockgether T, Schöls L, Abele M, Bürk K, Topka H, Andres F, et al. Age related axonal neuropathy in spinocerebellar ataxia type 3/Machado-Joseph disease (SCA3/MJD). J Neurol Neurosurg Psychiatry 1999;66:222-224.

24. Yatziv S, Russell A. An unusual form of metachromatic leukodystrophy in three siblings. Clin Genet 1981;19:222-227.

25. Tolosa E, Compta Y. Dystonia in Parkinson's disease. J Neurol 2006; 253 Suppl 7:VII7-VII13.

26. Schneider SA, Bhatia KP, Hardy J. Complicated recessive dystonia parkinsonism syndromes. Mov Disord 2009;24:490-499.

27. Klein C, Schneider SA, Lang AE. Hereditary parkinsonism: Parkinson disease look-alikes--an algorithm for clinicians to "PARK" genes and beyond. Mov Disord 2009. In Press.
28. Bozi M, Bhatia KP. Paroxysmal exercise-induced dystonia as a presenting feature of young-onset Parkinson's disease. Mov Disord 2003; 18:1545-1547.

29. Paisan-Ruiz C, Bhatia KP, Li A, Hernandez D, Davis M, Wood NW, et al. Characterization of PLA2G6 as a locus for dystonia-parkinsonism. Ann Neurol 2009;65:19-23.

30. Maltête D, Guyant-Maréchal L, Mihout B, Hannequin D. Movement disorders and Creutzfeldt-Jakob disease: a review. Parkinsonism Relat Disord 2006;12:65-71.

31. Hellmann MA, Melamed E. Focal dystonia as the presenting sign in Creutzfeldt-Jakob disease. Mov Disord 2002;17:1097-1098.

32. Sethi KD, Hess DC. Creutzfeldt-Jakob's disease presenting with ataxia and a movement disorder. Mov Disord 1991;6:157-162.

33. Wicki J, Germanier Y, Sztajzel R, Burkhard PR. Brueghel syndrome as a new manifestation of HIV encephalopathy. Eur Neurol 2008;60: 107-108.

34. Tan EK, Chan LL, Auchus AP. Hemidystonia precipitated by acute pontine infarct. J Neurol Sci 2005;234:109-111.

35. Bhatia KP, Marsden CD. The behavioural and motor consequences of focal lesions of the basal ganglia in man. Brain 1994;117:859-876.

36. Soland V, Evoy F, Rivest J. Cervical dystonia due to a frontal meningioma. Mov Disord 1996;11:336-337.

37. LeDoux MS, Brady KA. Secondary cervical dystonia associated with structural lesions of the central nervous system. Mov Disord 2003;18: 60-69.

38. Kim JW, Lee PH. Dystonic head tremor associated with a parietal lesion. Eur J Neurol 2007;14:e32-e33.

39. Khan AA, Sussman JD. Focal dystonia after removal of a parietal meningioma. Mov Disord 2004;19:714-716

40. Burguera JA, Bataller L, Valero C. Action hand dystonia after cortical parietal infarction. Mov Disord 2001;16:1183-1185.

41. Alarcón F, Tolosa E, Muñoz E. Focal limb dystonia in a patient with a cerebellar mass. Arch Neurol 2001;58:1125-1127.

42. Sethi KD, Adams RJ, Loring DW, el Gammal T. Hallervorden-Spatz syndrome: clinical and magnetic resonance imaging correlations. Ann Neurol 1988;24:692-694.

43. Chinnery PF, Crompton DE, Birchall D, Jackson MJ, Coulthard A, Lombès A, et al. Clinical features and natural history of neuroferritinopathy caused by the FTL1 460InsA mutation. Brain 2007;130: 110-119.

44. Hayflick SJ, Westaway SK, Levinson B, Zhou B, Johnson MA, Ching $\mathrm{KH}$, et al. Genetic, clinical, and radiographic delineation of Hallervorden-Spatz syndrome. N Engl J Med 2003;348:33-40.

45. Hayflick SJ. Neurodegeneration with brain iron accumulation: from genes to pathogenesis. Semin Pediatr Neurol 2006;13:182-185.

46. Magalhaes AC, Caramelli P, Menezes JR, Lo LS, Bacheschi LA, Barbosa ER, et al. Wilson's disease: MRI with clinical correlation. Neuroradiology 1994;36:97-100.

47. Saatci I, Topcu M, Baltaoglu FF, Köse G, Yalaz K, Renda Y, et al. Cranial MR findings in Wilson's disease. Acta Radiol 1997;38:250258.

48. Hitoshi S, Iwata M, Yoshikawa K. Mid-brain pathology of Wilson's disease: MRI analysis of three cases. J Neurol Neurosurg Psychiatry 1991;54:624-626.

49. Kenangil G, Ertan S, Sayilir I, Ozekmekçi S. Progressive motor syndrome in a welder with pallidal T1 hyperintensity on MRI: a twoyear follow-up. Mov Disord 2006;21:2197-2200.

50. Huang CC, Chu NS, Lu CS, Chen RS, Schulzer M, Calne DB. The natural history of neurological manganism over 18 years. Parkinsonism Relat Disord 2007;13:143-145.

51. Huang CC, Chu NS, Lu CS, Chen RS, Calne DB. Long-term progression in chronic manganism: ten years of follow-up. Neurology 1998; 50:698-700.

52. Josephs KA, Ahlskog JE, Klos KJ, Kumar N, Fealey RD, Trenerry MR, et al. Neurologic manifestations in welders with pallidal MRI 
T1 hyperintensity. Neurolog 2005;64:2033-2039.

53. Anderson JC, Costantino MM, Stratford T. Basal ganglia: anatomy, pathology, and imaging characteristics. Curr Probl Diagn Radiol 2004; 33:28-41.

54. Soffer D, Licht A, Yaar I, Abramsky O. Paroxysmal choreoathetosis as a presenting symptom in idiopathic hypoparathyroidism. J Neurol Neurosurg Psychiatry 1977;40:692-694.

55. Abbruzzese G, Rizzo F, Dall'Agata D, Morandi N, Favale E. Generalized dystonia with bilateral striatal computed-tomographic lucencies in a patient with human immunodeficiency virus infection. Eur Neurol 1990;30:271-273.
56. Tolge CF, Factor SA. Focal dystonia secondary to cerebral toxoplasmosis in a patient with acquired immune deficiency syndrome. Mov Disord 1991;6:69-72.

57. Choi IS, Cheon HY. Delayed movement disorders after carbon monoxide poisoning. Eur Neurol 1999;42:141-144.

58. Illum F. Calcification of the basal ganglia following carbon monoxide poisoning. Neuroradiology 1980;19:213-214.

59. Manyam BV, Walters AS, Narla KR. Bilateral striopallidodentate calcinosis: clinical characteristics of patients seen in a registry. Mov Disord 2001;16:258-264. 